\title{
Burden of Illness of Multiple Sclerosis: Part I: Cost of Illness
}

\author{
The Canadian Burden of Illness Study Group*
}

\begin{abstract}
Background: Multiple sclerosis (MS) is a common neurologic disease in young and middle-aged adults affecting approximately 35,000 Canadians. The objectives of this study were to estimate the annual and lifetime costs of MS from the Canadian societal perspective. Methods: Patients were consecutively recruited by neurologists in $14 \mathrm{MS}$ outpatient clinics across Canada. They were classified according to the Expanded Disability Status Scale (EDSS) into three groups: mild (EDSS $\leq 2.5$ ), moderate (EDSS = 3.0-6.0) and severe (EDSS $\geq 6.5$ ). Sociodemographic, clinical and resource utilization data were collected retrospectively for the three months prior to patient inclusion. Costing of resources was performed from Ministry of Health, private third party payers, patient and societal perspectives. Average Canadian costs (\$CDN 1995) were valued from available provincial data. Results: A total of 198 patients were included in the analysis (mild: $n=62$, moderate: $n=68$ and severe: $n=68$ ). Costs increased with increasing EDSS scores, from all perspectives. The annualized societal costs per patient were \$CDN14,523, \$CDN21,698 and \$CDN37,024 for the mild, moderate and severe groups, respectively. In all severity groups, most of the financial burden is borne by patients, from $74 \%$ to $88 \%$. Indirect costs, namely lost daily activity/leisure time and lost productivity, were the major societal cost drivers. The lifetime cost of MS, including patient institutionalization, was estimated to be \$CDN1,608,000 per patient. Conclusions: In Canada, MS is associated with enormous direct and indirect costs. Patients carry most of the economic burden of this disease. The results of this burden of illness study provide a basis for cost-effectiveness analyses of new therapeutic interventions for MS.
\end{abstract}

RÉSUMÉ: Fardeau de la maladie dans la SEP: Première partie: Coût de la maladie. Introduction: La sclérose en plaques (SEP) est une maladie neurologique fréquente chez les adultes jeunes et d'âge moyen. Environ 35,000 canadiens en sont atteints. Cette étude avait pour but d'évaluer les coûts annuels et à vie de la SEP sous l'aspect sociétaire au Canada. Méthodes: Des patients ont été recrutés consécutivement par des neurologues de 14 cliniques externes de SEP à travers le Canada. Les patients étaient classifiés selon l'échelle étendue de l'état d'invalidité (EDSS) en trois groupes: léger (EDSS $\leq 2.5$ ), modére (EDSS = 3.0-6.0) et sévère (EDSS $\geq 6.5$ ). Des données sociodémographiques, cliniques et sur l'utilisation des ressources ont été recueillies rétrospectivement sur une période de trois mois avant l'inclusion du patient dans l'étude. Le coût des ressources a été évalué du point de vue du Ministère de la santé, des assureurs privés, du patient et de la société. Le coût moyen en dollars canadiens (\$CDN1995) a été évalué a partier des données provinciales disponibles. Résultats: Au total, 198 patients ont été inclus dans l'analyse (groupe léger: $\mathrm{n}=62$, modéré: $\mathrm{n}=68$, sévère: $\mathrm{n}=68$ ). Les coûts ont augmenté avec l'augmentation des scores à l'EDSS, à tous les points de vue. Les coûts sociétaux annualisés par patient étaient de \$CDN14,523, \$CND21,698 et \$CND37,024 pour le groupe léger, modéré et sévère respectivement. Quelle que soit la sévérité, la plus grande partie du fardeau financier est assumée par le patient, soit entre 74 et $88 \%$. Les coûtes indirects, dont la perte des activités quotidiennes/des activités de loisirs et la perte de productivité constituaient les coûts les plus importants. Le coût à vie de la SEP, incluant l'institutionnalisation des patients, a été estimé à $\$ C D N 1,608,000$ par patient. Conclusions: Au Canada, la SEP est associée à des coûts directs et indirects énormes. Les patients assument la plus grande partie du fardeau économique de cette maladie. Les résultats de cette étude sur le fardeau de la maladie fournissent des données de base pour des analyses de coût-efficacité des interventions thérapeutiques nouvelles dans la SEP.

Can. J. Neurol. Sci. 1998; 25: 23-30

Multiple sclerosis is characterized by chronic inflammation, demyelination, and gliosis (scarring) within the central nervous system.' The exact etiology of MS is not fully understood. However, an autoimmune cause possibly triggered by viral infection in a genetically susceptible host has been hypothesized. ${ }^{2,3}$ From the average onset at about 30 years of age, MS runs through a variable course for the remainder of the patient's life frequently involving a development of disability with time. ${ }^{4}$ The effect of MS on life expectancy remains controversial. However, the disease has been reported to reduce the quality of life. ${ }^{4 \cdot 6}$

Second after trauma as the leading cause of neurologic disability in young and middle-aged adults, MS prevalence is influenced by geography and ethnic origin.' Women are about twice as likely to have the disease in comparison to men. ${ }^{1}$ With an
*The Canadian Burden of Illness Study Group included the following: MS Clinic Physicians: Dr. Anthony Auty (Winnipeg). Dr. Claude Bélanger (Québec). Dr. Jean-Pierre Bouchard (Québec), Dr. Donald G. Bunet (Kingston), Dr. Pierre Duquetic (Montráal), Dr. Gordon S. Francis (Montréal), Dr. Mark S. Freedman (Ottawa). Dr. Walter J. Hader (Saskatoon), Dr. Shawn C. Marshall (Saskatoon), Dr. Charles E. Maxner (Halifax), Dr. Luanne Metz (Calgary), Dr. Thomas-John Murray (Halifax), Dr. Paul O'Connor ('Toronto), Dr. Joël Oger (Vancouver). Dr. J.E. Paulseth (Hanilton), Dr. William E. Pryse-Phillips (St. John's), Dr. George P.A. Rice (London). MS Clinics coonlinators: Gwen Alcock (St. John's). Rozie Amaoutelis and Phillip Lewis (Montréal). Linda Armstrong (Halifax). Denise Boucher (Québec), Bev Davis (Winnipeg), Cathy Edgar (Kingston), Debra Hiser (Saskatoon), Jane Lesaux. Peggy Vandervoort, and Mary Hader (London), Sandra McGuiness (Calgary), Wendy Morrison, Jill Nelson and Debra Pack (Vancouver), Barbara Neufeld and Jo Anne Haynes (Hamilton), Maureen Perera (Toronto). Josése Poirier (Montréal), Kathy Stevenson (Ottawa). Quintiles Canada lnc.: Dr. Marc Riviere and Roma Tretiak. Berlex Canada Inc:: Manon Bélanger, Suzanne Laplante and Dr. JeanFrançois Grenier.

RECEIVED MAY 9, 1997. ACCEPTED IN FINAL. FORM AUGUST 26.1997.

Reprint requests to: Jean-François Grenier, Berlex Canada lnc., 2260 - 32nd Avenue, Lachine, Quebec, Canada H8T 3H4 
estimated 35,000 MS sufferers, Canada is a high frequency area with a prevalence ranging from 55 to 202 per 100,000 population. $^{7}$

Since MS is a chronic and disabling disease which affects young adults in their prime working years, it is costly to patients and to society. ${ }^{1.8}$ Studies regarding the economic burden of MS have been conducted in Europe and the USA ${ }^{8-10}$ The annual cost of MS to the UK society (1994), has been estimated to be f1.2 billion of which $24 \%$ was associated with lost productivity of the patient. ${ }^{8}$ The impact of MS on patients' ability to remain employed appears to be important. Studies have reported that 29 to 80 percent of MS patients are unemployed in the 10 years following disease onset. ${ }^{11,12}$ Other costs, such as medical and personal expenses, and the loss of leisure time have also been identified as contributors to the total cost of MS. - $^{8-10}$

An evaluation of the current cost of MS in Canada would be a useful tool to facilitate the planning and implementation of new management strategies for this chronic disease. The objectives of this study were to estimate the annual and lifetime costs of MS from the Canadian societal perspective.

\section{Methods}

Patient recruitment was performed by neurologists from 14 MS clinics in eight Canadian provinces (British Columbia, Alberta, Saskatchewan, Manitoba, Ontario, Quebec, Nova Scotia and Newfoundland). Local ethics committees reviewed and approved the study protocol. Patients were consecutively (not pre-selected) recruited from July to December 1995. Their informed consent was obtained. Patients eligible for enrollment had clinically or laboratory-supported definite MS according to the Poser criteria ${ }^{13}$ and were at least 18 years of age. Exclusion criteria for the study were: pregnancy or delivery in the last three months, any major acute or chronic disorder three months prior to inclusion in the study, any neurological illness apart from MS and recent participation in a pharmaceutical clinical trial.

Patients' disability level was rated by the investigator according to the Expanded Disability Status Scale (EDSS). Current EDSS scores were then used to balance accrual among three disability groups: mild (EDSS $\leq 2.5$ ), moderate (EDSS $=3.0-6.0$ ) and severe (EDSS $\geq 6.5$ ). For patients experiencing an MS exacerbation at the time of study assessment, the previous EDSS score recorded within one year prior to enrollment was used for disability grouping.

Data were recorded on a Case Report Form with patients and their families being the primary source of information. Clinic charts, hospital charts and summaries of medical history from other institutions were also used as source documents. Sociodemographic data, MS history since disease onset and resource utilization for the previous three months were collected. In addition to the direct medical and non-medical resource utilization, information regarding indirect costs was collected. The latter included: the number of "days missed from work" due to MS (for employed patients only) and the number of days lost for daily and leisure activities or "lost days" (for all patients) 14.15 (see Table 1).

Table 1: Resource Utilization and Source of Cost Data.

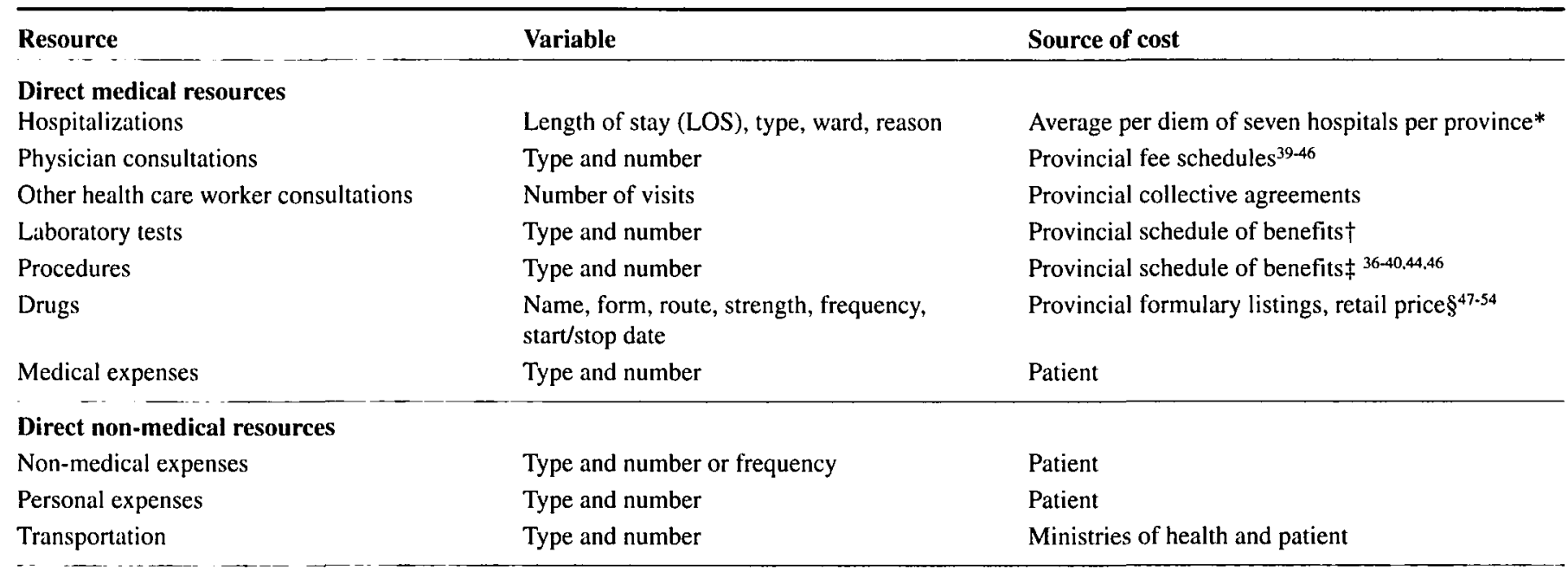

Indirect resources (patients only)

Lost productivity:

Days missed from work

(employed patients)

Foregone work income

(unemployed potentially active patients)

Lost time (leisure and unpaid activities)

\section{Number of days}

Number of days

Number of days
Average Canadian income ${ }^{26}$

Average Canadian income ${ }^{26}$

Average Canadian income ${ }^{26}$

* Per diem includes all medical and paramedical expenditures except physician consultations.

$\dagger$ In the province of Quebec, hospital costs were used.

¥ For MRI and CT scan, interprovincial billing rates were used.

$\S$ Manufacturer's sales price + mark-up + pharmacist's dispensing fee. 
A double data entry procedure with database quality control was used. Patients from all provinces were pooled in each disability group for the statistical analyses. Descriptive statistics were generated by EDSS-disability for sociodemography, clinical parameters and resource utilization.

All costs were evaluated in 1995 Canadian dollars (\$CDN). Cost valuation for the utilized resources was performed from Ministry of Health (MOH), private third party payer (TPP), patient and societal perspectives (see Table 1). The price of services (official tariffs or charges by providers) was used as a proxy of costs. Medical and non-medical direct costs were obtained from provincial reimbursement schedules, market prices and patients.

Indirect costs were estimated in accordance with the Human Capital Approach ${ }^{15-17}$ i.e., the cost of using resources (such as person days) is the value of the benefits they would have generated in their best alternative use (e.g., income). ${ }^{14.16}$ The loss of productivity was estimated according to the following formulas:

- Cost of days missed from work for employed patients:

"Days missed from work" X Average daily Canadian income

- Cost of foregone income for "potentially active"Note ${ }^{1}$ unemployed patients:

"Lost days" X \% of active Canadians employed $(90 \%))^{17} \mathrm{X}$ $6 / 9$ Note 2 X Average daily Canadian income

Finally, the valuation of lost time for unpaid functions such as household duties, education and recreational activities was made by multiplying the number of "lost days" reported by the average Canadian daily income. As per the Human Capital Approach, the addition of foregone work income to the total cost does not represent double counting as it is assumed that "lost days" lead to the loss of both the working and the nonworking portions of a day.

Using the pooled population, province-specific costs were applied to all resources to determine average and median cumulative cost per patient, by severity group, and over the threemonth period for each perspective for the provinces of British Columbia, Alberta, Saskatchewan, Manitoba, Ontario, Quebec and Nova Scotia. Costs for Nova Scotia were used to estimate the costs for the Maritimes. Costs to the various payers and to society were calculated by summing the costs by resource category as detailed in Table 2 . For each resource, the cost contribution for each perspective was determined with no overlap or double counting between perspectives. Average Canadian costs were determined from these provincial data and annual costs were derived from the three-month data. For calculation of national annual costs (per patient, per severity group), the provincial costs were weighted by population as determined by the 1991 census. ${ }^{18}$

Univariate linear regression was performed on total annual societal cost to identify the main sociodemographic and clinical predictors.

To calculate the annual cost of MS to the Canadian society, the MS population of Canada (est. 35,000) ${ }^{7}$ was classified into DSS severity groups according to the data reported by Weinshenker et al., 1989.5 The DSS severity groups were converted into the mild, moderate and severe EDSS groups as
Table 2: Sum of Costs From the Societal and Payer Perspectives.

\begin{aligned} \hline Ministry of Health cost $= &$ SHospitalization $+\sum$ Physician's fees + \\ & $\sum$ Allied health care $+\sum$ Labs \& Procedures \\ & $+\sum$ Medication $+\sum$ Transportation (ambu- \\ & lance) $+\sum$ Medical/Non-medical expenses \\ & $+\sum$ Personal expenses. \end{aligned}

Third Party Payer cost ${ }^{*}=\Sigma$ Medication $+\Sigma$ Medical/Non-medical expenses $+\sum$ Personal expenses $+\sum$ Dilys missed from work.

Patient cost $\dagger=\quad \sum$ Medication $+\sum$ Transportation (car. taxi. public transport $+\sum$ Medical/Non-medical expenses $+\Sigma$ Personal expenses $+\sum$ Days missed from work $+\sum$ Foregone work income $+\sum$ Time lost.

Societal cost $=$ $\Sigma \mathrm{MOH}+\Sigma \mathrm{TPP}+\Sigma \mathrm{PT}$

- Some items may appear in more than one perspective. No double counting has been done. Costs used for calculation of each perspective, represent the part of the costs paid by a given payer. For example, some medications may have been paid entirely or partly by the Ministry of Health (MOH), a third party payer (TPP) and patients.

* Costs were included only for patients with private insurance coverage, excluding any resources (or part of) covered by the $\mathrm{MOH}$.

$\dagger$ Expenses (or part of) paid by patients and not reimbursed by either the MOH or a TPP.

defined in the present study. The annual cost estimates per disability group determined in this paper were then applied. The sum of these costs per disability category resulted in the total societal cost of MS. Finally, the average annual cost per patient was determined by dividing the above total by the estimated prevalence.

To estimate the average lifetime cost of MS, an MS disease progression model was constructed. The costs were projected over a period of 45 years. Since the impact of MS on survival is controversial, forty-five years was chosen as it reflects the average age of onset ( 30 years) and the average Canadian life expectancy ( 75 years). ${ }^{19}$ The average annual progression rate for each DSS level up to DSS 7, derived from Weinshenker et al. $1989,{ }^{20}$ was applied to the model. Patients surviving up to DSS 8 were assumed to have a mean survival of 45 years after MS onset. The average annual cost for each severity stage was then multiplied by the estimated mean time spent at each stage from the model to derive the average lifetime cost. A discount rate of $5 \%$ per year was finally applied to obtain the discounted lifetime cost. ${ }^{21}$ With this first scenario, costs associated with patients' institutionalization were not considered (Scenario A).

In order to estimate the average lifetime cost of MS including institutionalization, a second scenario was developed (Scenario B). Due to the generally bedridden condition of patients at DSS 8 and above, it was assumed that these patients would be institutionalized once their disability level is attained. Time to reach DSS 8 and above is not well covered in the relevant literature. Therefore, it was assumed that the last 11 years of the patient's lifetime would be spent at DSS 8 and above, which created a

Note I Retired patients, homemakers and unemployed patients of 60 years and over, were excluded from these calculations as they were not considered "active". Note $26 / 9$ represents the proportion of working days in a 3-month period, i.e., 60 days $/ 90$ days. 
scenario with a fourth stage. The annual Ontario institutional per diem served to calculate the average cost at this latter stage. ${ }^{22}$ Overall, an average patient was assumed to spend the first decade with the disease in the mild group, the second decade in the moderate group, 14 years between DSS 6 and DSS 8 and the remaining 11 years at DSS 8 and above. Constant and discounted lifetime costs were then calculated.

\section{Results}

A total of 208 MS patients from eight provinces were recruited in the study. Ten patients (mild stage $=3$, moderate stage $=6$ and severe stage $=1$ ) were excluded from the analysis as they were treated with an interferon- $\beta$. This was done in order to maintain the focus of this study on the supportive care of MS. Of the 198 subjects analyzed, 62 patients were classified in the mild stage, 68 in the moderate stage and 68 in the severe stage. All patients except one were seen at the MS clinics as outpatients.

The sociodemographic patient profile is reported in Table 3. Despite their relatively young age, the employment status of patients was greatly impacted at an early stage of the disease. Thirty-seven percent $(37 \%)$ of patients in the mild group had already experienced a change in their employment status because of MS. As the disease progressed, an increased proportion of patients had to modify their employment status; $82 \%$ in the severe group. Before MS onset, $80 \%$ to $91 \%$ of patients who subsequently changed employment because of MS were employed at full time. In the mild group at a mean age of 39.8 years, only $37 \%$ of patients were employed full time. With disease progression, only $28 \%$ and $4 \%$ in the moderate and severe disease stages remained on full time employment, respectively. Consequently, patient income (all sources combined) declined as MS progressed. Among mild disability stage patients, $66 \%$ of them had a gross annual income below $\$ C D N 30,000$ per year. In the severe group, $85 \%$ had a gross annual income below this level. With disease progression, both patient and household incomes declined. As disease progressed, less salary income, more disability and retirement benefits and more financial assistance from relatives were reported.

Clinical data are summarized for the three disability groups in Table 4. The median EDSS scores were 2.0, 4.5 and 7.5 at entry for the mild, moderate and severe groups, respectively. The majority of mild stage patients $(79 \%)$ had a relapsing-remitting form of MS. In the moderate group, the majority of patients had a relapsing-remitting or a secondary progressive form of the disease ( $43 \%$ for each type). In the most severe stage, patients were split between secondary and primary progressive forms of the disease $(57 \%$ and $41 \%$ respectively). The proportion of patients in the mild stage experiencing exacerbations at the time of the visit was considerably higher $(21 \%)$ than in the two other disability groups ( $12 \%$ and $4 \%$ ).

Total MS costs by perspective are presented in Table 5. From the societal perspective, the mean annual cost per patient was $\$ C D N 14,523, \$ C D N 21,698$ and \$CDN37,024 in the mild, moderate and severe groups, respectively. Patient costs accounted for $83 \%$ of the total cost in the mild stage, $88 \%$ in the moderate and $74 \%$ in the severe stage (see Figure).

The distribution of societal costs according to the type of resource for the three severity groups is presented in Table 6 .

Table 3: Socio-Demographic Profile by EDSS Severity Group.

\begin{tabular}{|c|c|c|c|}
\hline Variables & $\begin{array}{c}\text { EDSS } \leq 2.5 \\
(n=62)\end{array}$ & $\begin{array}{l}\text { EDSS 3.0-6.0 } \\
\quad(n=68)\end{array}$ & $\begin{array}{c}\text { EDSS } \geq 6.5 \\
(n=68)\end{array}$ \\
\hline $\begin{array}{l}\text { Age (years) } \\
\text { mean } \pm \mathrm{SD}\end{array}$ & $39.8 \pm 9.5$ & $45.2 \pm 10.7$ & $49.6 \pm 12.2$ \\
\hline Female $[\mathrm{n}(\%)]$ & $53(85 \%)$ & $44(65 \%)$ & $49(72 \%)$ \\
\hline $\begin{array}{l}\text { Married/Cohabiting [n (\%)] } \\
\text { Education level [n (\%)] } \\
\text { high school and lower } \\
\text { post secondary and higher }\end{array}$ & $\begin{array}{l}43(69 \%) \\
24(39 \%) \\
38(61 \%)\end{array}$ & $\begin{array}{l}48(71 \%) \\
26(38 \%) \\
42(62 \%)\end{array}$ & $\begin{array}{l}52(76 \%) \\
23(34 \%) \\
45(66 \%)\end{array}$ \\
\hline $\begin{array}{l}\text { Current employment status [n (\%)] } \\
\text { Employed } \\
\text { Full-time } \\
\text { Part-time } \\
\text { Unemployed } \\
\text { Other }\end{array}$ & $\begin{array}{r}23(37 \%) \\
13(21 \%) \\
18(29 \%) \\
8(13 \%)\end{array}$ & $\begin{array}{r}19(28 \%) \\
7(10 \%) \\
30(44 \%) \\
12(18 \%)\end{array}$ & $\begin{array}{r}3(4 \%) \\
4(6 \%) \\
39(57 \%) \\
22(32 \%)\end{array}$ \\
\hline $\begin{array}{l}\text { Change of employment due to MS } \\
\text { [n (\%)] }\end{array}$ & $23(37 \%)$ & $42(62 \%)$ & $56(82 \%)$ \\
\hline Prior full time employed [n (\%)] & $21(91 \%)(n=23)$ & $35(83 \%)(n=42)$ & $45(80 \%)(n=56)$ \\
\hline $\begin{array}{l}\text { Patient total gross annual income } \\
\text { mean } \pm S D\end{array}$ & $\begin{array}{l}\$ 24,865 \\
\pm \$ 19,693\end{array}$ & $\begin{array}{l}\$ 23,260 \\
\pm \$ 20,914\end{array}$ & $\begin{array}{l}\$ 19,725 \\
\pm \$ 17,057\end{array}$ \\
\hline $\begin{array}{l}\text { Household total gross annual incom } \\
\text { mean } \pm \text { SD }\end{array}$ & $\begin{array}{r}\$ 56,077 \\
\pm 33,071\end{array}$ & $\begin{array}{l}\$ 46,052 \\
\pm \$ 28,704\end{array}$ & $\begin{array}{l}\$ 45,731 \\
\pm \$ 27,882\end{array}$ \\
\hline $\begin{array}{l}\text { Patient's contribution to } \\
\text { household total income }\end{array}$ & $44 \%$ & $51 \%$ & $43 \%$ \\
\hline
\end{tabular}


The cost associated with patients' lost time was the most important cost driver representing $58 \%, 58 \%$ and $41 \%$ in the mild, moderate and severe groups, respectively.

The univariate regression analysis indicated that none of the following variables had a significant impact on cost (p-value $>0.05$ ): age, gender, education level (high school and lower versus above high school), patient income (lower than or equal to $\$ 30,000$ versus higher), and age at disease onset.

One-way ANOVA was performed on age at disease onset, years since disease onset and total cost in order to compare the three disease severity groups (mild, moderate and severe). As expected, there was no significant difference in the age at disease onset among the three groups ( $p$-value $>0.05$ ). Time since disease onset among the three groups showed a significant difference with a p-value of 0.0001 .

The average lifetime cost of MS per patient, excluding institutionalization, was estimated to be $\$ C D N 1,205,000$ ( $\$ C D N 383,000$ when discounted at 5\%). Lifetime cost including institutionalization, was estimated to be \$CDN1,608,000 (\$CDN441,000 when discounted at 5\%).
Based on an average cost of $\$ C D N 29,100$ per patient per year, with the current estimated prevalence of $\mathrm{MS}$, the annual cost of this disease to the Canadian society is about \$CDNI.0 billion.

\section{Discussion}

The present study has both strengths and limitations. The pragmatic design allowed for a realistic estimation of the costs associated with ambulatory MS patients who attend specialized clinics across Canada. As a result of this open approach, no sample size calculations were performed to ensure the representativity of the study population with respect to the national MS population. However, comparison with published sociodemographic and clinical reports suggests that the study population is representative of similar MS populations in North America with respect to age, sex, age at onset, and disease history including frequency of exacerbations..$^{5.23 .24}$ In the context of the Canadian health system, a study conducted in MS clinics is close to a general MS patient population study as approximately $80 \%$ of MS patients attend MS clinics. However, resource utilization for

Table 4: MS Medical History by EDSS Severity Group.

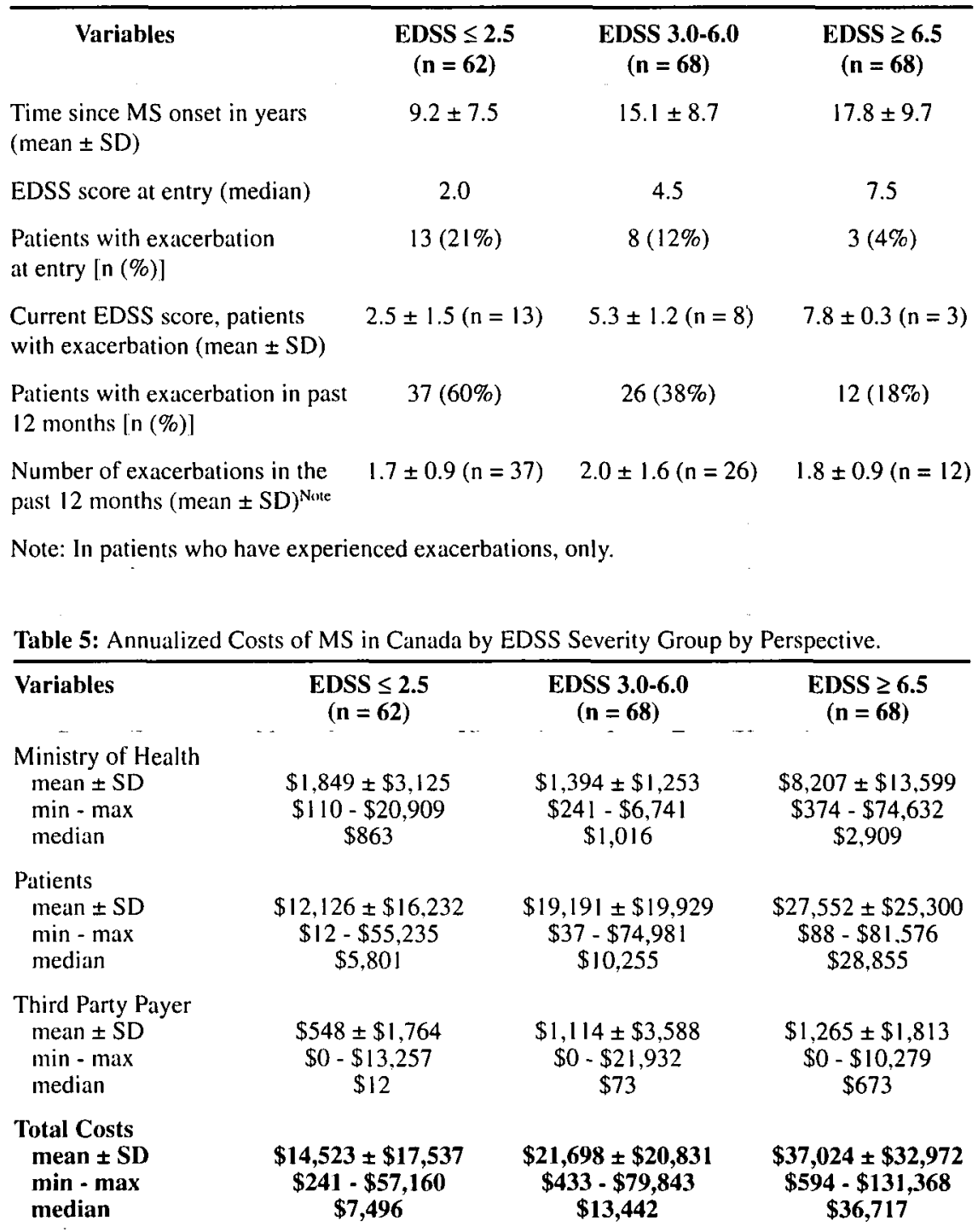




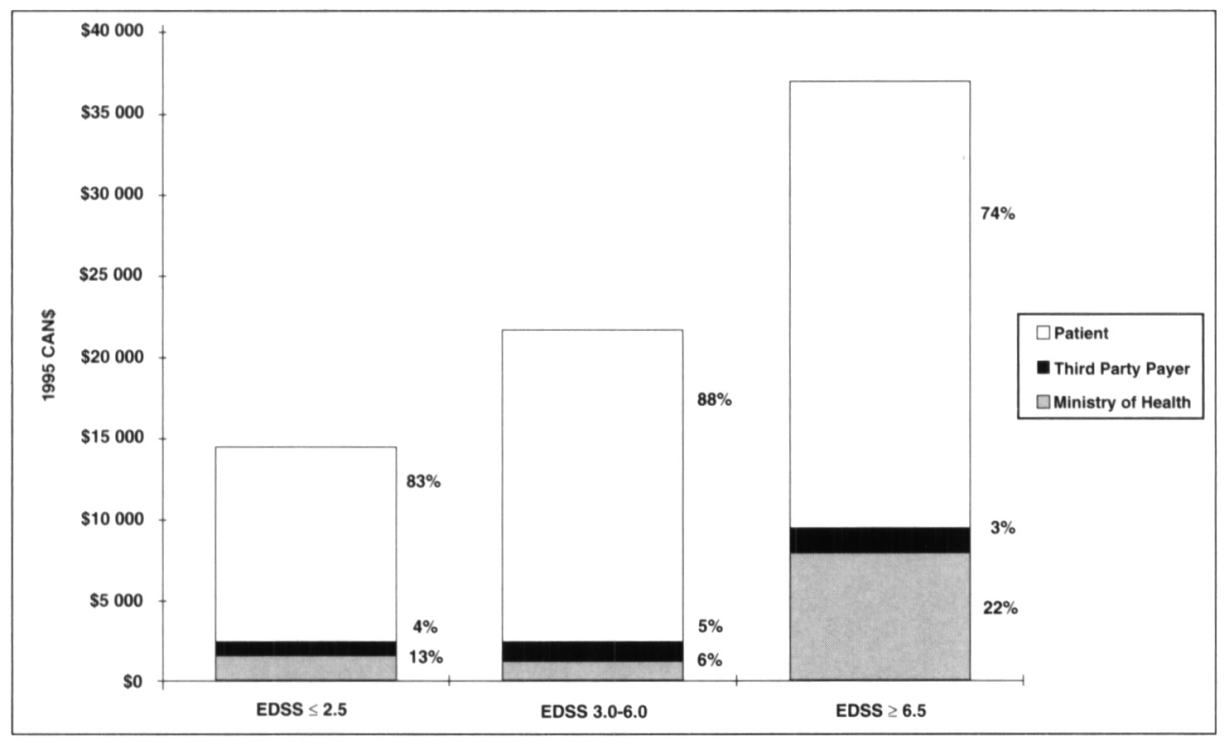

Figure: Annual costs, share of the financial burden.

institutionalized patients was not captured by this outpatient design. For lifetime cost evaluation, this component had to be modeled. Because of the profound effect of discounting on costs occurring late in the disease, the imprecision deriving from this last part of the model appeared to be minimal. (Discounted costs scenario A: $\$ C D N 383,000$ vs. scenario B: $\$ C D N 441,000$.)

The cross-sectional design and the use of three-month data to estimate annual resource utilization of a long term chronic disease such as MS may have limited the scope of the study, i.e., certain events may not have been captured in the three-month period (e.g., hospitalization of moderate stage patients). In addition, the estimates for daily activity/leisure time lost may not have represented the true cost to society and patients: people usually tend to place a higher value on their leisure time than on their working hours. ${ }^{25}$ In calculating the indirect costs, it was assumed that the average Canadian income ${ }^{26}$ would be representative of patients' earning power. This assumption may have underestimated these costs since our study population reported a higher education level compared to the average Canadian population. ${ }^{27}$ Finally, since a societal rather than a global economic perspective was taken, psychic and intangible costs were not included in the study. Despite the above limitations, this study presents the first Canadian estimate of the annual direct and indirect costs for MS patients attending outpatient MS clinics.

One major observation in the present study is the early withdrawal of MS patients from active life. The patient unemployment rates increase with EDSS score. For example, unemployment in the mild group is almost three times higher

Table 6: Annualized Canadian Societal Costs for EDSS Severity Groups by Resource Category.

\begin{tabular}{|c|c|c|c|}
\hline Resources & $\begin{array}{c}\text { EDSS } \leq 2.5 \\
(n=62)\end{array}$ & $\begin{array}{l}\text { EDSS 3.0-6.0 } \\
(n=68)\end{array}$ & $\begin{array}{c}\text { EDSS } \geq 6.5 \\
(n=68)\end{array}$ \\
\hline & Mean cost $(\%)$ & Mean cost $(\%)$ & Mean cost $(\%)$ \\
\hline Direct medical resources & $\$ 2,250(15.5)$ & $\$ 1,969(9.1)$ & $\$ 7,233(19.5)$ \\
\hline Hospitalization & $\$ 469(3.2)$ & $\$ 0(0.0)$ & $\$ 3,123(8.4)$ \\
\hline Physician consultations & $\$ 789(5.4)$ & $\$ 696(3.2)$ & $\$ 858(2.3)$ \\
\hline $\begin{array}{l}\text { Consultations with other health } \\
\text { care workers }\end{array}$ & $\$ 217(1.5)$ & $\$ 431(2.0)$ & $\$ 624(1.7)$ \\
\hline Laboratory tests & $\$ 63(0.4)$ & $\$ 54(0.2)$ & $\$ 110(0.3)$ \\
\hline Procedures & $\$ 293(2.0)$ & $\$ 74(0.3)$ & $\$ 208(0.6)$ \\
\hline Drugs & $\$ 400(2.8)$ & $\$ 594(2.7)$ & $\$ 1,434(3.9)$ \\
\hline Medical expenses & $\$ 19(0.1)$ & $\$ 119(0.5)$ & $\$ 877(2.4)$ \\
\hline Direct non-medical resources & $\$ 912(6.3)$ & $\$ 1,663(7.7)$ & $\$ 7,787(21.0)$ \\
\hline Non-medical expenses & $\$ 45(0.3)$ & $\$ 398(1.8)$ & $\$ 2,076(5.6)$ \\
\hline Personal expenses & $\$ 544(3.7)$ & $\$ 516(2.4)$ & $\$ 4,191(11.3)$ \\
\hline Transportation & $\$ 324(2.2)$ & $\$ 747(3.4)$ & $\$ 1,521(4.1)$ \\
\hline Indirect resources & $\$ 11,360(78.2)$ & $\$ 18,068(83.3)$ & $\$ 22,002(59.5)$ \\
\hline $\begin{array}{l}\text { Days missed from work } \\
\text { or "Sick Leaves" }\end{array}$ & $\$ 937(6.5)$ & $\$ 1,464(6.7)$ & $\$ 54(0.1)$ \\
\hline Foregone work income & $\$ 1,962(13.5)$ & $\$ 4,103(18.9)$ & $\$ 6,666(18.0)$ \\
\hline Time lost & $\$ 8,461(58.3)$ & $\$ 12,501(57.6)$ & $\$ 15,282(41.3)$ \\
\hline Total & $\$ 14,522$ & $\$ 21,698$ & $\$ 37,024$ \\
\hline
\end{tabular}


than the Canadian unemployment rate of $10 \%{ }^{18}$ and in the severe group almost six-fold higher. The increasing unemployment rate over time and with disability is consistent with the findings of a German study which reported unemployment rates from $29 \%$ to $50 \%$ over the 20 years following the onset of MS symptoms. "The impact of MS on employability appears particularly clear when one examines the full time employment observations. For example, only $37 \%$ of mild stage patients worked on a full time basis, whereas this percentage is $85 \%$ for the agematched Canadian population. ${ }^{18}$ As reported in the relevant medical literature, patients frequently change the nature of their work or workload as the MS progresses (e.g., from physical work to desk work) ${ }^{28.29}$ Such a tendency is also observed in our study. Change in employment due to MS (mainly switching from full time to another category) reaches $82 \%$ in the severe disability group. 11,30

From the societal perspective, the annual total cost per patient is \$CDN14,523, \$CDN21,698 and \$CDN37,024 for the mild, moderate and severe EDSS disability stages, respectively. The national average per patient (all severity groups considered) cost is \$CDN29,109. Three other interesting economic studies regarding MS have been published. ${ }^{8-10}$ However, comparison of the present results with these is difficult since methodologies and means of defining disability vary between each other.

In 1993, Bourdette et al. estimated the annual costs per patient to be $\$ U S 35,000 .{ }^{9}$ This retrospective American study involved 165 veterans ( $89 \%$ male) with moderate to severe MS (average EDSS 6.1). In contrast to the present study, this American study included VA benefits (pensions and compensation for disability) as well as nursing home costs which together represented $47 \%$ of the cost. Lost productivity and lost time were not included.

The results of our study also indicate that costs from the patient perspective are the largest contributors to societal cost. These costs can be insurmountable. It has been reported that even with health insurance, up to $28 \%$ of families with MS sufferers in Canada are unable to afford the prohibitive costs of the illness. ${ }^{30}$

Indirect costs are the most important cost drivers, representing more than half of the costs in all severity groups with the largest portion being lost time. The remainder of indirect costs is lost productivity which represents $18 \%$ to $26 \%$ of total costs including days missed from work in employed patients as well as the foregone work income in unemployed patients. In a mailsurvey study conducted in the UK, Holmes et al. 1995 found a similar importance of lost productivity $\left(24 \%\right.$ of total cost) ${ }^{8}$ In 1984, Inman estimated the annual cost of MS to be up to \$US 15,000 (or \$US40,200 in 1996 dollars) Note 1 for severe patients in their prime working years. Lost earnings represented from $73 \%$ to $87 \%$ of the total costs for severely limited patients.

The annual national cost of MS in Canada is estimated to be \$CDN1.0 billion. This is higher than the cost of asthma (\$CDN504 million, 1990) and all infectious diseases in Canada (\$CDN772 million) despite much higher prevalence than MS.31${ }^{33}$ In contrast, our findings are lower than the cost of cardiovascular disease (\$CDN7,742 million) and cancer (\$CDN11, 189 million), two conditions which are also much more prevalent than MS. ${ }^{31}$ These comparisons suggest that untreated MS in Canada is very costly. Any reduction in the global economic consequences of MS through new effective treatments would be of benefit to MS patients and the Canadian society.

The average lifetime cost of MS is estimated to be \$CDN1,607,000 (\$CDN 441,000 when discounted at 5\%). Other studies dealing with lifetime costs are few and comparison difficult since the course of MS is unpredictable and data over a patient's entire lifetime generally unavailable..$^{4.6}$ Inman et al. (1984) estimated the lifetime costs (direct and indirect) to be $\$$ US 151,000 in 1976 dollars (or US\$404,680 adjusted to 1996 dollars). The findings of these studies suggest that treatment efforts should focus at the early stages of the disease. The immediate aim would be to impact on factors which determine patients' employability, while ultimately treatment should aim at slowing disability progression. ${ }^{12.34}$

With the introduction of treatments which specifically target the underlying disease, namely interferon beta- $1 b$ in Canada, and interferon beta-la and copolymer- $I$ in the United States, the cost structure of MS will be altered substantially. While drug costs will obviously increase, other direct medical, non-medical and indirect costs have the potential to be reduced significantly. According to the current indications, it is estimated that approximately 10 to $15 \%$ of MS patients will be treated with these innovative therapies. ${ }^{35}$ Future studies will determine the cost-effectiveness of these treatments in the relevant MS patient sub-population over a 5 to 10 year time period.

\section{Conclusions}

The results of this study provide a solid baseline against which the economic impact of new and developing MS therapies can be measured and management strategies tested. The striking contribution to societal cost of lost time indicates that further elucidation of the impact of MS will necessarily come from a quality of life analysis such as that presented later in this issue. MS is an expensive disease and much of the economic burden falls upon patients and their families. In addition to the effect on a patient's life, lost productivity also impacts Canadian society and therefore any treatment that would slow disease activity and improve quality of life would be beneficial to MS sufferers and to society.

\section{ACKNOWLEDGEMENTS}

This study was made possible by a grant from Berlex Canada Inc.

\section{REFERENCES}

I. Hauser SL. Multiple sclerosis and other demyelinating diseases. In: Isselbacher KJ, Braunwald E, Wilson JD, Martin JB, Fauci AS, Kasper DL, eds. Harrison's Principles of Internal Medicine. Toronto: McGraw Hill Inc., 1994: 2281-2294.

2. Hibbard PL. The use and misuse of statistics for epidemiological studies of multiple sclerosis. Ann Neurol 1994; 36(S2): S218S230.

3. Becker CC, Gidal BE, Fleming JO. Immunotherapy in multiple sclerosis, part 1. Am J Health-Syst Pharm 1995; 52: 1985-2000.

4. Weinshenker BG. The natural history of multiple sclerosis. Neurol Clin 1995; 13(1): 119-146.

5. Weinshenker BG, Bass B, Rice GPA, et al. The natural history of multiple sclerosis: a geographically based study. I. Clinical course and disability. Brain 1989; 112: 133-146. 
6. Sadovnick AD, Ebers GC, Wilson RW, Paty DW. Life expectancy in patients attending multiple sclerosis clinics. Neurology 1992; 42: $991-994$.

7. Sadovnick AD, Ebers GC. Epidemiology of multiple sclerosis: a critical overview. Can J Neurosci 1993; 20: 17-29.

8. Holmes J, Mawick T, Bates D. The cost of multiple sclerosis. Brit J Med Econ 1995; 8: 181-193.

9. Bourdette DN, Prochazcha AV, Mitchell W, Licari P, Burks J. VA MS Rehabilitation Study Group. Health care costs of veterans with MS: implications for the rehabilitation of MS. Arch Phys Med Rehabil 1993; 74: 25-31.

10. Inman RP. Disability indices, the economic costs of illness and social insurance: the case of multiple sclerosis. Acta Neurol Scand Suppl 1984; 70: 46-55.

11. Bauer HJ, Firnhaber W, Winkler W. Prognostic criteria in multiple sclerosis. Ann NY Acad Sci 1965; 122(1): 542-551.

12. Kornblith AB, La Rocca NG, Baum HM. Employment in individuals with multiple sclerosis. Int J Rehab Research 1986; 9(2): 155-165.

13. Poser CM, Paty DW, Scheinberg L, et al. New diagnostic criteria for multiple sclerosis: guidelines for research protocols. Ann Neurol 1983; 13: 227-231.

14. Koopmanschap MA, Rutten FFH. A practical guide for calculating indirect cost of disease. PharmacoEconomics 1996; 10(5): 460466.

15. Posnett J, Jan S. Indirect costs in economic evaluation: the opportunity cost of unpaid inputs. Health Econ 1996; 5: 3-23.

16. Drumond MF. Resource allocation decisions in health care: a role for quality of life assessments? J Chron Dis 1987; 40(6): 605-616.

17. Statistics Canada. Catalogue 71-001. Labour Force Catalogue, 1996.

18. Statistics Canada. Catalogue 93-301. A National Overview: Population Dwelling Counts, 1993.

19. Statistics Canada. Catalogue 84-537. Table de mortalité: Canada et provinces, 1990-1992.

20. Weinshenker BG, Bass B, Rice GPA, et al. The natural history of multiple sclerosis: a geographically based study: 4. Applications to planning and interpretation of clinical therapeutic trials. Brain 1991; 114: 1057-1067.

21. Freund DA, Dittus RS. Principles of pharmacoeconomic analysis of drug therapy. PharmacoEconomics 1992; $1(1): 20-32$.

22. Ministry of Health. Finance and Administration Division. Fiscal Strategies Branch. Authorized rates 1996-1997 Public Hospitals.

23. Hohol MJ, Orav EJ, Weiner HL. Disease steps in multiple sclerosis. Neurology 1995; 45: 25I-255.

24. Lynch S, Rose J. Multiple sclerosis. Disease-a-month 1996; XLII (1): 3-55.

25. Drummond MF, Stoddart GL, Torrance GW, eds. Cost effectiveness analysis. In: Methods for the economic evaluaton of health care programmes. New York: Oxford University Press, 1986: 75-111.

26. Statistics Canada. Catalogue 13-207. Annual Income Distribution by Size in Canada, 1994

27. Statistics Canada. Catalogue 95-326. Profile of census divisions and sub-divisions in Quebec: Part B, 1991.

28. Scheinberg L, Holland N, La Rocca N, et al. Multiple sclerosis: earning a living. Arch Neurol 1982; 39: 1395-1401.

29. Mitchell JN. Multiple sclerosis and the prospects for employment. J Soc Occup Med 1981; 31: 134-138.
30. Catanzaro $M$, Weinert $C$. Economic status of patients living with multiple sclerosis. Int J Rehab Research 1992; 15: 209-218.

31. Krahn MD, Berka C, Langlois P, Detsky AS. Direct and indirect costs of asthma in Canada, 1990. Can Med Assoc J 1996; 154: $821-831$.

32. Glaxo Canada Inc. The Costs of Adult Asthma in Canada; Comm. Media for Educ., Inc.; 1993.

33. Dales RE, Raizenne M, El-Saadany S, Brook J, Burnett R. Prevalence of Childhood Asthma across Canada. Int J Epidemiol 1994; 23(4): 775-781.

34. Compston A. Beta-interferon and multiple sclerosis: not a final solution to the problem. Brit J Hosp Med 1995; 53(11): 547-553.

35. According to internal estimates by Berlex Canada, Inc. Data on file at Berlex.

36. British Columbia Ministry of Health. BCMA Schedule of Costs by Fiscal Year. British Columbia: Medical Services Plan, 1994.

37. Alberta Health. Schedule of Medical Benefits. Alberta: Health Care Insurance Plan, 1994.

38. Saskatchewan Health. Payment Schedule for Physician Service. Saskatchewan: Medical Care Insurance Branch, 1996.

39. Manitoba Health. Physician's Manual. Manitoba: Health Services Insurance Plan, 1996

40. Ontario Ministry of Health. Schedule of Benefits/Physician Services. Ontario: Health Insurance Act, 1992.

41. Ministère de la Santé et des Services Sociaux. Centres Hospitaliers Publics-Listes 1994-1995. Québec.

42. Direction Général du Budget et de l'Administration/Direction de la Planification et des Stratégies de Financement, 1995.

43. Ministère de la Santé et des Services Sociaux. Manuel des Médecins Omnipraticiens. Québec: La Régie de l'AssuranceMaladie, 1995.

44. Ministère de la Santé et des Services Sociaux. Manuel des Médecins Spécialistes. Québec: La Régie de l'Assurance-Maladie, 1995.

45. Maritime Medical Care Incorporated. Physician's Manual. Nova Scotia: Medical Services Insurance, 1994.

46. Maritime Medical Care Incorporated. Laboratory Credit Schedule. Nova Scotia: Department of Health \& Fitness, 1994.

47. Pharmacare. Low Cost Alternative/Reference Based Pricing List. British Columbia: Pharmacare, 1995.

48. Alberta Health. Drug Benefits List. Alberta: Family and Social Services, 1994.

49. Saskatchewan Health. Drug Formulary. Saskatchewan: Prescription Drug Services, 1996.

50. Manitoba Health. Drug Benefits And Interchangeability Formulary. Manitoba: Drug Standards \& Therapeutics Committee, 1996.

51. Ontario Ministry of Health. Drug Benefits Formulary/Comparative Drug Index. Ontario: Publication Ontario, 1995.

52. Association Québécoise des Pharmaciens Propriétaires. Listes de Médicaments-AQPP. Montréal: Association Québécoise des Pharmaciens Propriétaires, 1996.

53. Services des Communications. Listes de Médicaments-4e Éditions. Québec: La Régie de l'Assurance-Maladie, 1996.

54. Nova Scotia Pharmacare. Maximum Allowable Cost List. Nova Scotia: Pharmacare Program, 1994. 